\title{
ESPAÇOS DO POSSÍVEL NA PESQUISA EM ARTE E EM EDUCAÇÃO
}

\author{
Aurélia Regina de Souza Honorato ${ }^{1}$
}

\begin{abstract}
Resumo
O texto que apresento fala de uma trajetória de pesquisa na busca de encontros com possibilidades de pesquisa em arte e em educação, que escapam dos tradicionais procedimentos metodológicos estabelecidos na academia. Uma trajetória que apresenta no percurso experiências com dispositivos inaugurais nos campos e que se consolidaram como alternativas na produção de conhecimento de pesquisa. Estes formatos metodológicos, que são abertos para múltiplas combinações, se mostraram potentes e abriram-se para acolher, nas pesquisas individuais e também nas coletivas do Grupo de Pesquisa em Arte, o que chamamos de Espaços do Possível. Espaços que buscam deslocar intencionalmente modos instituídos de se fazer pesquisa e conhecimentos em arte e em educação, ao aceitar e ressaltar categorias como incerteza, imaginação, ilusão, introspecção, visualização e dinamismo.
\end{abstract}

Palavras-chave: Pesquisa, metodologia, arte, educação.

\section{POSSIBLE SPACES IN RESEARCH IN ART AND EDUCATION}

\begin{abstract}
The text I present speaks of a research trajectory in search of encounters with methodological possibilities of research in art and education that escape the traditional methodological procedures established in the academy. A trajectory that presents in the course experiences with inaugural procedures in the fields and that have consolidated as alternatives in the production of research knowledge. These methodological formats, which are open to multiple combinations, have proved to be powerful and have opened up to welcome, in the individual researches and also in the Group of Research in Art, what we call Possible Spaces. Spaces that seek to intentionally displace instituted ways of doing research and knowledge in art and education by accepting and emphasizing categories such as uncertainty, imagination, illusion, introspection, visualization and dynamism.
\end{abstract}

Keywords: Research, methodology, art, education.

\footnotetext{
${ }^{1}$ Doutora em Ciências da Linguagem, professora do Curso de Artes Visuais Licenciatura e Bacharelado da Universidade do Extremo Sul Catarinense e Professora de Artes na Educação Básica da rede estadual de Santa Catarina. Email: arh@unesc.net
}

Criar Educação, Criciúma, v. 7, no1, jan/jul 2018.- PPGE - UNESC 


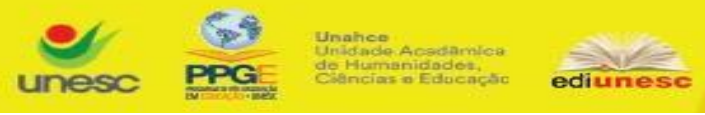

O que trago para partilhar com vocês é o anúncio de uma discussão sobre os desafios de se fazer pesquisa buscando escapar das metodologias tradicionais que engessam a escrita e o pensamento. É um texto que contextualiza meu percurso de pesquisa e minhas escolhas na criação de desvios que me permitiram caminhar nas margens das tradições metodológicas das academias.

Minha trajetória na pesquisa sempre foi marcada pela ideia da experiência como espaço de mudança. A concepção de experiência, desde a modernidade, tem sido a relação do sujeito consigo mesmo e com o mundo. E é na experiência que o ser humano, por meio de seus sentidos, reconhece o mundo ao seu redor e reconhece a si mesmo.

Nessa esteira, Jorge Larrosa (2011) apresenta experiência como aquilo que se dá na relação entre o conhecimento e a vida. Em 1987 concluí minha especialização em Arte e Educação, a pesquisa de final de curso que realizei intitulou-se Abram alas o teatro está entrando nas escolas. Nela me dediquei a discutir as possibilidades de transformação e mudanças nas escolas e em seus alunos e professores a partir da experiência com o teatro. Uma pesquisa bibliográfica em que não me permiti ir a campo, nem a conversar com pessoas sobre meus questionamentos, o que fiz foi percorrer escritos de teóricos relacionando com minha trajetória de professora de Artes na escola pública. Ali já me colocava como sujeito na pesquisa.

Em 2007 apresentei minha dissertação de mestrado: As experiências com literatura nos relatos das crianças: abrindo espaços de narrativa. Foi um tempo de dedicação na pesquisa com crianças. Tive como objetivo ouvir o que as crianças pensam sobre suas experiências com a literatura, em particular na escola procurando responder a alguns questionamentos como: Que acontecimentos da vida de uma pessoa funcionam como desencadeadores de uma relação amorosa com a literatura? Qual o papel da escola nesta relação? Que ingredientes existentes na vida e ausentes (ou não) na escola operam na formação do leitor? 
Essa minha preocupação aparece pelo fato de considerar que a leitura e a escuta atentas são partes constituintes da tomada de consciência do sujeito produtor de sentidos. E que eu me constituo na relação com o outro. Que ler e escrever, escutar e falar - é colocar-se em movimento; é sair para além de si mesmo; é manter sempre aberta a interrogação acerca do que se é. E que o combate das palavras ainda não ditas contra as palavras já ditas favorece a ruptura do horizonte dado, permite que o sujeito se invente de outra maneira, que o eu seja outro.

Como metodologia para este estudo investi em um procedimento novo na época chamado Espaços de Narrativa e que hoje já está consolidado como uma metodologia de pesquisa e que se aproxima muito das metodologias em arte que estamos estudando e desenvolvendo no momento. Salgado et al (2005) sublinham que a investigação que provoca espaços de narrativa traz consigo uma "intenção dialógica na produção do conhecimento crítico entre adultos e crianças" (p.13) possibilidade de diálogo entre crianças e adultos apontada, não apenas como princípio metodológico, mas como princípio educativo.

E em 2015 defendi minha tese de doutorado intitulada Trajetórias cartográficas na formação de professores e professoras de Artes: espaços do possível. Uma pesquisa em que me aventurei a escolher como método de pesquisa a cartografia. O termo cartografia, como possibilidade metodológica, surge com Gilles Deleuze e Félix Guattari (1995) no texto em que escrevem a quatro mãos ainda na década de 80: Mil Platôs: do capitalismo à esquizofrenia. É um conceito que se assume implicado com a invenção e a criação, pois permite pensar uma pesquisa das multiplicidades que produz multiplicidades.

Desenhar linhas, investigar territórios, perceber as margens e os deslocamentos, criar e estimular mudanças nas possíveis trajetórias. E é com Suely Rolnik, que a cartografia entra no campo das pesquisas acadêmicas no Brasil. Para a autora "a cartografia é um método com dupla função: detectar a paisagem, seus acidentes, suas mutações e, ao mesmo tempo, criar vias de passagem através deles" (ROLNIK, 1987. p. 6). Este método apresenta também a figura do cartógrafo, aquele que "[...] serve-se de fontes as mais variadas, incluindo fontes não só escritas 
e nem só teóricas. Seus operadores conceituais podem surgir tanto de um filme, quanto de uma conversa ou de um tratado de filosofia" (ROLNIK, 2014. p. 65).

A cartografia, nesse estudo, se configurou como uma maneira, um método, de potencializar pensamentos na tentativa de ampliar as possibilidades de pesquisar em arte, em linguagens, em educação. Se pensarmos na constituição de uma pesquisa no contexto da ciência moderna, iremos encontrar em diferentes publicações referentes a metodologia de pesquisa, passos a serem seguidos (coleta, análise, discussão) onde cada momento da pesquisa traz consigo o anterior, que traz o anterior, prolongando-se numa sequência ordenada até o final. Procurei na investigação, processual, construir uma escrita que apresenta os dados produzidos no percurso, assim como os resultados obtidos objetivando destacar o caráter coletivo desta construção.

Coletivo no sentido de diferentes vozes se articulando para construir pensamentos sobre as relações existentes e possíveis da, e na, formação de professoras e professores de Artes nos diversos territórios que se constituem nestas relações e que foram marcados por caracterizarem meu campo de pesquisa, que são: o ensino da arte, a experiência, o sensível, a criação, a imagem. Territórios que se engendram, se interconectam com seus fluxos e movimentos promovendo pensamentos.

\section{Os caminhos que buscamos}

Buscando apresentar em minhas pesquisas a experiência como mudança de modos de vida, vejo que vim transpondo barreiras metodológicas trazidas pela academia, subvertendo na forma da escrita, trazendo o eu para a pesquisa, investigando possibilidades de transgressão na arte e pela arte. A partir de meu lugar de professora de Artes na Educação Básica e formadora de professores e artistas na universidade é que hoje desenvolvo junto ao Grupo de Pesquisa em Arte, - GPA, estudos investigativos sobre modos de fazer pesquisa em arte e em educação. Nele nos colocamos alguns desafios que são: Compreender, a partir de leituras e debates, similaridades e aproximações entre diferentes tipologias de pesquisas em arte, em termos formais e metodológicos, tendo como parâmetros as 
ideias e os conceitos das metodologias PBA - Pesquisa Baseada em Arte e PEBA Pesquisa Educacional Baseada em Arte.

Ampliar o repertório de imagens da arte e da cultura visual dos participantes do grupo na perspectiva da elaboração de textos reflexivos sobre a pesquisa em arte e em educação. Socializar os estudos provenientes do diálogo entre pesquisa, metodologias, arte, cultura, educação oportunizando a apresentação e discussão de pesquisas desenvolvidas pelos integrantes do Grupo e por pesquisadores convidados.

Oportunizar o exercício do pensar a pesquisa em arte como uma forma de agenciar pesquisadores e espectadores na ampliação da compreensão da experiência como um espaço do possível. Participar de eventos cujos temas tenham como parâmetros as ideias e os conceitos das metodologias PBA - Pesquisa Baseada em Arte e PEBA - Pesquisa Educacional Baseada em Arte.

O desafio das investigações baseadas em arte é poder ver as experiências e os fenômenos aos que dirige sua atenção a partir de outros pontos de vista e formular questões que outras maneiras de fazer pesquisa não são capazes de realizar. [...] só podemos fazê-lo considerando a utilização das imagens ou representações artísticas visuais ou performativas como elemento essencial da representação das experiências dos sujeitos. (HERNÁNDEZ, 2010. p. 45)

O trabalho desenvolvido pelo grupo de pesquisa em arte GPA/UNESC/CNPq durante o período de agosto de 2016 a julho de 2017 teve como foco diferentes modos de pensar a pesquisa em arte e em educação a partir de referencial teórico, em especial, produzido por Belidson Dias e Rita Irwin na obra: Pesquisa Educacional Baseada em Arte A/R/TOGRAFIA (2013).

Esta obra se propõe a buscar caminhos de ruptura com os modos estabelecidos de se fazer pesquisa, pois em oposição ao positivismo os autores buscam apontar que o domínio social e cultural demonstra ser um agente basilar na construção do conhecimento. O estudo, neste período, fez os pesquisadores do grupo perceberem e confirmarem que a pesquisa baseada em arte se constitui, cada vez mais, em espaço de construção de saberes em arte e em educação. 
O Grupo de Pesquisa em Arte - GPA - UNESC/CNPq vem se constituindo um importante espaço de discussão para a ampliação do conhecimento da pesquisa em arte e sobre arte. Nesse sentido, sentimos a constante necessidade de (re)significarmos nossas ações frente a essa área de conhecimento que nos desafia constantemente. Buscamos, assim, ampliar essas discussões a partir da seguinte problemática: Como deslocar modos estabelecidos de se fazer pesquisa e conhecimentos em arte que tragam o tema para a discussão, objetivando conhecer as metodologias de pesquisa conhecidas como PBA - Pesquisa Baseada em Arte e a PEBA - Pesquisa Educacional Baseada em Arte, que nascem do desejo de pesquisadores norte-americanos e europeus compreenderem, valorarem e conceberem a produção em arte como uma modalidade de pesquisa?

Nosso interesse foi adentrar nos estudos da Pesquisa Baseada em Arte, "[...] que é um gênero emergente e em processo de expansão de pesquisa e investigação nas Ciências Sociais e Ciências Humanas” (DIAS, 2013. p.13). No Brasil a ABNT é a mais comum norma de escrita acadêmica que as IES seguem e utilizam, já em outros países de maior produção técnico/científico/artístico, já existem aproximadamente mais de três mil estilos de redação acadêmica em acordo com tipos e áreas de conhecimentos de periódicos e instituições educacionais (DIAS, 2013).

Observamos em publicações de pesquisadores, professores e alunos da área da arte, na academia, que suas escritas ainda seguem acriticamente um modelo positivista. Esta constatação tem feito muitos pesquisadores das universidades brasileiras que trabalham na formação de profissionais da área da arte buscarem caminhos de ruptura com os modos estabelecidos de se fazer pesquisa, pois em oposição ao positivismo estes pesquisadores buscam apontar que o domínio social e cultural demonstra ser um agente basilar na construção do conhecimento.

Os encontros do grupo promoveram mudanças nas formas de pensar a pesquisa acadêmica e na compreensão da imagem da arte e da cultura visual como dispositivo de narrativas e construção de conhecimentos e isso contribuiu para a ampliação do referencial teórico e artístico para a pesquisa. 
GPA aprovou um plano de trabalho no edital no 261/2015 Processo de Seleção Programa de Grupos de Pesquisa 2016-2017 intitulado A pesquisa baseada em arte. Neste plano diferentes atividades foram previstas e as que foram realizadas se constituem primeiramente em reuniões mensais de estudo. Os integrantes se encontram para trocas de experiência com a pesquisa em arte e estudo dos textos pensados para a ampliação do repertório teórico e artístico do grupo.

Também foi feito um mapeamento dos grupos de pesquisa do território nacional que desenvolvem pesquisas com base na Pesquisa Baseada em Arte. Dos grupos pesquisados alguns integrantes do grupo visitaram dois destes grupos: o GPCVE - O grupo de pesquisa em cultura visual e educação da Universidade Federal de Goiás, o Grupo ARTEVERSA - da Universidade Federal do Rio Grande do Sul. E com o Grupo Entre Paisagens, da Universidade Estadual de Santa Catarina mantivemos contato virtual. Além das visitas feitas a estes grupos, integrantes deles estiveram na Unesc para conversa com o GPA.

O impacto e resultados desse desafio se fez e, ainda se faz, no campo da formação de professores de Artes e também de artistas que se debruçam sobre a pesquisa, o ensino e a extensão na universidade, assim como nos diversos espaços de educação e pesquisa em que atuam. Acredita-se, assim, que a imersão neste estudo contribuiu e, ainda tem muito a contribuir, com as pesquisas em arte e em educação que são desenvolvidas no âmbito dos Cursos de Graduação em Artes Visuais da UNESC, nas duas habilitações Bacharelado e Licenciatura, nos Cursos de Especialização das áreas da arte e da educação da UNESC, assim como nas pesquisas individuais dos pesquisadores e estudantes que compõem o grupo.

Hoje, aqui, estamos neste processo. E espero que minhas aventuras nos territórios da pesquisa no campo da arte e da educação possam contribuir para repensar de forma mais ampla a formação de pesquisadores na perspectiva da renovação da percepção do mundo, assim como contribuir para novos olhares teórico-metodológicos de pesquisa. 


\section{Referências}

DELEUZE, Gilles; GUATTARI. Félix. Mil platôs: capitalismo e esquizofrenia 2, vol. 1. Tradução de Ana Lúcia de Oliveira, Aurélio Guerra Neto e Célia Pinto Costa. São Paulo: Editora 34, 1995.

ROLNIK, Suely (1987): Cartografia Sentimental da América: produção do desejo na era da cultura industrial. 250f. Tese. (Doutorado em Psicologia Social). Pontifícia Universidade Católica de São Paulo. Programa de Pós-Graduação em Psicologia Social.

, Suely. Cartografia Sentimental: Transformações Contemporâneas do desejo.2 $2^{a}$ edição. Porto Alegre: Sulina; Editora da UFRGS, 2014. 247p.

SALGADO, Raquel Gonçalves, RIBES, Rita Marisa \& JOBIM E SOUZA, Solange. Pela tela, pela janela: questões teóricas e práticas sobre infância e televisão, In Caderno Cedes. Campinas: UNICAMP, n. 65, jan / abr 2005.

Recebido em dezembro 2017 Aprovado em fevereiro 2018 